\title{
FOMO, JOMO and COVID: How Missing Out and Enjoying Life Are Impacting How We Navigate a Pandemic
}

\author{
Stephanie Jacobsen \\ Bridgewater State University
}

This paper presents the trends of FOMO (Fear of missing out) and JOMO (Joy of missing out) and how they have remained and possibly increased in importance during a global pandemic. Both constructs are explained, and the negative consequences of FOMO are detailed. How consumers FOMO has led to increased consumption during the pandemic is explained. JOMO is presented as a cure for FOMO in general, and especially during a pandemic. JOMO is a more suitable alternative that leads to increased overall satisfaction and a more optimistic outlook.

Keywords: FOMO, JOMO, pandemic consumption

\section{INTRODUCTION}

The Fear of Missing out (FOMO) became a household acronym at the beginning of the decade. The term was first written about by Dan Herman (2000) as an explanation for why consumers may be less loyal or practicing increased brand switching. FOMO is defined as "an underlying form of anxiety that we're missing out on something or that other people are having more fun than us (Rees, 2017, para. 3)." Research suggests the causes of FOMO include social media and increased social pressure (Rees, 2017; Fuller, 2018). FOMO can reduce our satisfaction with our own lives and experiences, and lead to a grass is greener mentality (Przybylski et al., 2013). If FOMO leads to an increase in consumer dissatisfaction, it creates a difficult challenge for marketers. Social comparison is a key driver for many consumption exchanges, however less overall satisfaction is a consumption outcome typically avoided (Hill, Martin \& Chaplin, 2012). If FOMO causes a consumer to believe what others have is better than what they have, they may feel like they purchased an inferior option. If this is the case, is there potentially a more beneficial marketing strategy that can overcome the negative impacts of FOMO?

The Joy of Missing Out (JOMO) is the opposite of FOMO, and is about disconnecting, opting out and being comfortable with where you are (Phelan, 2018). Various definitions and explanations of JOMO can be found. Cording (2018) and Rees (2017) sum up JOMO by focusing on the now. "JOMO is essentially about being present and okay with where you're at. It's about tuning out the noise and letting go of the "shoulds" and of worrying you're doing something wrong or could be making a better choice" (Cording, 2018, para. 5). According to Rees (2017) JOMO inspires us to focus on what we want, and how we feel right now. It motivates us to devote our time and energy to things that bring joy. No matter what we choose to do, or opt out of, it is the intention that is important.

While both JOMO and FOMO have been playing a role in our behavior and our consumption, a global pandemic has drastically impacted how exactly we are missing out. From panic buying to spring break 
parties, we have seen consumers express their desire to participate in life, and still have all the essentials at home. This paper aims to discuss the impacts of FOMO and JOMO, how the pandemic has changed things, and suggests JOMO as an important step in improving quarantine.

\section{FOMO}

Studies have estimated that nearly $70 \%$ of adults in developed countries suffer from FOMO (Schreckinger, 2014). Researchers have investigated where or how this idea of FOMO originated. Lai, Altavilla, Ronconi and Aceto (2016) found that FOMO causes greater brain activity that indicates it stems from a neurological need to belong. Clinical Psychologist Anita Sanz (2015) supports the findings by Lai et al. (2016), that FOMO stems from our brain, however she cites a more anthropological cause. She describes FOMO as essential to our survival since the time of the caveman. If we did not find out where a food source was located or clean drinking water, we could die. Therefore, FOMO was a key driver of life.

Dan Herman first became aware of the idea of FOMO during a focus group study in 1996 (Herman, 2011). Four years later he published an article in the Journal of Brand Management defining and explaining the concept of FOMO (Herman, 2000). Since Herman's article, the idea of FOMO has grown considerably. Przybylski et al. (2013) define FOMO as "a pervasive apprehension that others might be having rewarding experiences from which one is absent" (p. 1). FOMO can leave you feeling anxious that something exciting is happening elsewhere without you.

FOMO can have other psychological implications for individuals. A 2018 study of college freshman found that young people frequently experience FOMO, and that FOMO is associated with fatigue, stress, and trouble sleeping. This wasn't just experienced by those who were left out or not social. No matter how enjoyable the activity they selected, they still felt strongly that they were missing out, leading to negative feelings and being distracted when thinking of or being presented with any alternative activity (Milyavskaya et al., 2018). Baker et al. (2016) found that those who experienced higher levels of FOMO had more depressive symptoms, were less attentive, and displayed more physical symptoms. Riordan et al., (2015) found that FOMO can lead to higher alcohol consumption. A study by J. Walter Thompson (2011) found that FOMO contributes to a person's overall dissatisfaction with their social lives and leads to the feeling of having less. This causes unwanted feelings (boredom, loneliness etc.) and negatively impacts well-being.

Research is underway to discover the impact of FOMO on consumers. While the aforementioned research demonstrates a lack of satisfaction overall, does this translate to the consumption experience? Current evidence shows that FOMO makes consumers want to participate in the activity they may be feeling left out of or purchase the product they feel they should have that someone else (or many others) have. Researchers have found that FOMO increases consumption. Taylor (2019) found that FOMO motivates consumers to engage in conspicuous consumption through social media. FOMO was also found to lead to increased conformity consumption of culturally associated brands (Kang, et al., 2019).

FOMO can lead to obsessive behavior or consumption. Studies have found evidence of smart phone and alcohol addiction caused by FOMO (Wolniewicz, et al., 2018; Riordan et al., 2015). FOMO also leads to impulse purchasing and impulse purchasing leads to an increase in post-purchase regret (Saleh, 2012; Çelik et al., 2019). Bushra and Bilal (2014) studied whether these regretful impulse purchases were caused by internal factors (FOMO, materialism, etc.) or sales, displays and marketing strategies. They found that internal factors like FOMO were causing the compulsive buying that led to regret.

Recently, a solution to these negative feelings of missing out has been discovered, offering potential for increased overall satisfaction.

\section{JOMO}

While FOMO has many negative side effects, many have embraced the newer more beneficial trend of JOMO. "JOMO is the emotionally intelligent antidote to FOMO and is essentially about being present and being content with where you are at in life (Fuller, 2018, para. 4)." Instead of a sense of fear, there is a joy and happiness in knowing you chose to be doing exactly what you are doing, instead of any other activity (Dodgson, 2018a). Blogger Anil Dash first coined the term JOMO in a popular blog post in 2012 when he realized, after having a baby boy, that he would rather be having bath time with his son, than doing anything 
else (Dash, 2012). Due to Dash's blog, JOMO was mentioned in a New York Times article by Jenna Wortham (2012) and was on J. Walter Thompsons annual list of things to watch in 2013.

Similar to FOMO, it took several more years before the idea of JOMO really took off. In Spring 2018, Sundar Pichai, the C.E.O. of Google, took the stage at the company's annual developer conference with the words "Joy of Missing Out" projected behind him. By summer, many began taking notice of this idea of JOMO. Articles appeared in Psychology Today, Inc, the LinkedIn Blog, Forbes, Business Insider and the New York Times (Decembrele, 2018; Phelan, 2018; Bariso, 2018; Fuller, 2018; Dodgson, 2018a; Cording, 2018). The topic was even featured on the CBS Morning Show in December 2018 and an episode of the television show Younger (Miller, 2018; Seong-yoon, 2019). Today, JOMO is being touted as the latest travel trend (Felepchuk, 2020). Travelers are choosing low traffic areas and traveling off season versus choosing a more Instagram worthy trip. Even Subaru is using it to advertise safety by opting for low stakes enjoyable outings in place of "high-octane" pursuits (Dhaliwal, 2020).

JOMO is characterized by a specific choice to engage in a behavior. It's not about focusing on missing out on fun things -it is making the decision to do whatever you find enjoyable, which can be anything from playing with a pet to a fancy night on the town (Bradshaw, 2019). While FOMO involves negative feelings of fear, anxiety and regret, JOMO focuses more on engagement, fulfillment and both reconnecting and disconnecting (Dodgson, 2018a; Cording, 2018; Rees, 2017).

\section{FOMO and JOMO During a Pandemic}

Most people can experience both FOMO and JOMO, depending on their outlook and desire for social inclusion. What happens, then, when the world slows down due to a global pandemic? Immediately, FOMO consumption began. Months later panic buying is still creating shortages in many segments (Pearson, 2020). On March 12,2020 purchases of toilet paper increased 734\% compared with the same day the previous year (Wieczner, 2020). Then we started making bread at home, causing a yeast shortage when sales rose $647 \%$ in March compared to the previous year (Castrodale, 2020). We also bought bread makers (sales increased sixfold), pasta makers (462\% increase) and deep freezers (45\%) (Kary, 2020). Clorox wipes immediately sold out and were still hard to find as Fall approached.

Next, we decided we wanted to ride bicycles for exercise. According to the New York times, "Sales of commuter and fitness bikes ... increased 66 percent, leisure bikes jumped 121 percent, children's bikes went up 59 percent and electric bikes rose 85 percent" (Goldbaum, 2020). As cold weather approached, purchases of outdoor heaters at one big box store increased 1,500\% (Harder, 2020). All of this buying has been fueled by new product needs, a fear of shortages, and social influence. When one person makes sourdough bread, we are all inspired to do the same.

When one person wants to go out to a party during a pandemic, what happens? Similar to how social influence can lead to an increase in consumption, it can also lead to mirroring behaviors. When we see others having fun, being with family and friends or having any social interaction at all, what do we think? For some, FOMO hits hardest here and we feel the need to go out and do the same. This can lead to risky behaviors that can threaten lives when undertaken during a pandemic. For others, attending social gatherings is a terrifying thought, for fear of catching a threatening virus (Baker, 2020).

So where does this leave us? We are isolated, mostly in our homes, and sick of baking sourdough. This is where JOMO offers an interesting alternative. JOMO presents ways to embrace our new and challenging situation safely (Lahiri, 2020; Dar, 2020; Gabaji, 2020; Fernandez \& Matt, 2020). JOMO suggests savoring the time we have with those in our household, taking the time for self-improvement and self-care. In true JOMO fashion, this means everything from binge watching shows on streaming services (up $85 \%$ according to Nielsen) to more quality family time. In a survey of 2,000 Americans, $75 \%$ of parents said that they were able to experience a key moment or milestone they otherwise might have missed during the pandemic. The same study found that nearly $80 \%$ of participants learned more about their children's hobbies and passions, $48 \%$ learned more about what their spouse actually does for work, and $77 \%$ were enjoying spending more time with the members of their household (OnePoll, 2020). Embracing the joy of the small things can help get us through and keep us safe. 
In order to demonstrate the presence of JOMO and FOMO and their co-existence, to further support this research, a study was conducted.

\section{HYPOTHESES}

While many popular news articles have been written about JOMO, theoretical research has not actually been done to demonstrate its existence and relationship to FOMO. Currently there is anecdotal evidence that JOMO causes increased feelings of joy, contentment, engagement and fulfillment (Dash; 2012; Fuller, 2018; Bradshaw, 2019; Rees, 2017). In comparison, FOMO has been shown to cause numerous negative psychological outcomes including fatigue, stress, trouble sleeping, depressive symptoms and less mindful attention, dissatisfaction with life, loneliness, boredom and low self-esteem (Milyavskaya et al., 2018; Baker et al., 2016; J. Walter Thompson, 2011; Dodgson, 2018b). Therefore, it is expected that,

H1: Those who experience JOMO feel more positive about missing out than those experiencing FOMO.

Two recent articles on JOMO and tourism found that many travelers are utilizing JOMO, seeking places that are more authentic or off the grid, instead of popular tourist sites (Putra, 2019; Felepchuk, 2020). Anecdotally, many articles describe disconnecting activities such as Dash's bath time (typically bubble bath and bath toys are involved here) or Netflix/television viewing, which require products/consumption prior to the experience. During the pandemic, consumption related to tv/movie viewing, and together time (puzzles, cooking products) as well as personal time (exercise equipment, home spa kits) allowed consumers to experience JOMO, while panic buying allowed consumers to fully give into FOMO. JOMO buying seems to proceed or enable JOMO activities while feelings of FOMO seem to lead to consumption. It is expected that both JOMO and FOMO can involve consumption, however that the consumption occurs during different times.

H2: FOMO occurs during the experience while JOMO is likely to occur prior to the experience.

There is anecdotal evidence that consumers are happy when experiencing JOMO (Dodgson, 2018; Cording, 2018; Rees, 2017), and that they partake in consumption. Therefore, it seems likely those who experience JOMO will be happier with their product experience than those who experience FOMO which is correlated with negative feelings. FOMO leads to increased post-purchase regret which causes consumer dissatisfaction (Saleh, 2012; Çelik et al., 2019; Bushra \& Bilal, 2014). Therefore:

H3: Those who experience JOMO have higher levels of customer satisfaction than those who experience FOMO.

\section{METHODOLOGY}

This study has a between-subjects design with participants being randomly assigned to one of two groups (JOMO and FOMO). Post-purchase satisfaction was measured as a dependent variable while selfmonitoring was measured as a potential moderator. The participants missing out experience (JOMO vs. FOMO) was manipulated by having them think of a missing out time (as used by Yi \& Baumgartner, 2008). Participants assigned to the JOMO condition were asked to describe a time they experienced the joy of missing out, what they did during this time and why. Responses were screened for JOMO experiences. All were deemed appropriate activities. There were two independent coders and disagreements were resolved by discussion (interrater reliability was .98).

The participants assigned to the FOMO were asked to describe a time they experienced FOMO, what they missed out on, and why they felt they missed out. Descriptions were again screened, looking specifically for occurrences that were based on being excluded instead of missing out. Most involved missing out due to illness, work or family responsibilities. All were found to be appropriate. Next, 
participants were asked a series of questions about their state of missing out. Similar to study 1, using 5point scales, participants were asked how they felt when they missed out (happy to sad). Next, they were asked if they used or purchased any products during this time and to evaluate their post-purchase satisfaction. This was measured using a series of statements about the participants' behavioral intentions towards the retailer in order to understand post-purchase outcomes (Cronin et al. 2000; $\alpha=.97$ ).

\section{RESULTS}

Of the 237 participants who took the survey 20 were removed due to a lack of completion, leaving a usable sample of 217 . The age of participants ranged from 18-63, while the majority of participants (81.1\%) were 18-23. Fifty-five percent of participants were male.

H1: Those who experience JOMO feel more positive about missing out than those experiencing FOMO.

Thirty-five percent of participants admitted to experiencing FOMO when seeing others doing something they are not. Those who experienced FOMO described missing a party or social gathering. Participants were asked if they ever decided not to participate in a social event in order to do something more enjoyable and less social. Over $90 \%$ of participants said they did this at least some of the time. Participants described their JOMO experiences including spending time with family or relaxing by themselves. When asked how they felt when they skipped an event, those who experienced JOMO (M=3.69, $\mathrm{t}(93)=35.974, \mathrm{p}=.000)$ were significantly happier than those who experienced FOMO $(\mathrm{M}=2.27, \mathrm{t}$ $(108)=29.120, \mathrm{p}=.000)$.

H2: FOMO occurs during the experience while JOMO is likely to occur prior to the experience.

There was a significant difference between product usage during JOMO $(\mathrm{M}=2.29,(\mathrm{t}(102)=16.894$, $\mathrm{p}=.000)$ and FOMO $(\mathrm{M}=2.09, \mathrm{t}(119)=18.134, \mathrm{p}=.000)$, with more usage during JOMO. Most participants (41\%) used a product or service during their JOMO experience that they had already purchased previously, while 3\% bought something new.

During FOMO participants were less likely to use products and about $9 \%$ of participants bought something new. The most common items purchased were food (dominoes, candy). Most often participants experiencing FOMO spent time on their phones looking at social media.

H3: Those who experience JOMO have higher levels of customer satisfaction than those who experience FOMO.

The main effect of state of missing out was significant $(t(45)=59.947, \mathrm{p}=0.000)$. Customer satisfaction with the product purchased or used during missing out was higher in the JOMO condition $(\mathrm{M}=3.76)$ than in the FOMO condition $(\mathrm{M}=1.46)$

\section{DISCUSSION AND IMPLICATIONS}

The results of this study show that while FOMO is very real for consumers, so is JOMO and the desire to disconnect in a more positive way. It is also important to note that JOMO tends to lead to more consumption than FOMO. So, while some organizations use FOMO as a strategy, this may not be effective, in addition to the negative psychological impact of FOMO. Allowing consumers to feel more joy during a consumption experience is not only a more sound marketing strategy, but it also reduces these negative impacts.

This study demonstrates that consumers do experience JOMO and FOMO. JOMO makes us significantly happier than FOMO. Consumption allows us to enjoy these JOMO experiences and can facilitate them but the overall satisfaction we feel is undoubtedly positive. 


\section{LIMITATIONS, DIRECTIONS FOR FUTURE RESEARCH AND CONCLUSION}

This study just begins to scratch the surface of the relationship between JOMO and FOMO. There are several limitations to this study that could be improved upon. Data was collected at only one university and is therefore not necessarily generalizable. This study should be replicated on a more national (or international) level to really measure the impact of JOMO. The majority of participants are young and though reflective of the generation that is most embracing JOMO, does not give any indication of the way older generations are reacting to JOMO. Future research should determine how brands have been impacted both by FOMO and JOMO.

We know that JOMO and FOMO are occurring. We have watched consumption trends and human behavior change throughout the pandemic. If JOMO and FOMO have been key drivers for consumption and engagement during the pandemic, what does that mean for our lives moving forward? When this is all over, will we once again give each other FOMO with all of our activities and consumption, or will we have been inspired to seek out simpler options to bring us joy? Only time will tell, but just as JOMO was becoming a preferred pre-pandemic alternative, it may have helped many of us get us through a pandemic and continue to keep us grounded when it's over.

\section{REFERENCES}

Baker, T. (2020, October 22). FOMO is real during quarantine season. The Famuan.

Baker, Z.G., Krieger, H., \& LeRoy, A.S. (2016). Fear of missing out: Relationships with depression, mindfulness, and physical symptoms. Translational Issues in Psychological Science, 2(3), 275.

Bariso, J. (2018, July 23). Meet JOMO: The emotionally intelligent response to FOMO. Inc.

Bradshaw, F. (2019, September 26). Are you afraid of missing out? replace FOMO with JOMO and rediscover your inner peace. Mind Tools Blog. Retrieved from https://www.mindtools.com/blog/fear-and-joy-of-missing-out/

Bushra, A., \& Bilal, A. (2014). The relationship of compulsive buying with consumer culture and postpurchase regret. Pakistan Journal of Commerce and Social Sciences (PJCSS), 8(3), 590-611.

Castrodale, J. (2020, April 16.). Our Pandemic Baking Binges are Causing a Yeast Shortage. Food \& Wine.

Çelik, I.K., Eru, O., \& Cop, R. (2019). The effects of consumers' FOMO tendencies on impulse buying and the effects of impulse buying on post-purchase regret: An investigation on retail stores. BRAIN. Broad Research in Artificial Intelligence and Neuroscience, 10(3), 124-138.

Cording, J. (2018, July 21). Is the Joy of Missing Out the New Self-Care? Forbes.

Cronin, J.J., Brady, M.K., \& Hult, G.T.M. (2000). Assessing the effects of quality, value and customer satisfaction on consumer behavioral intentions in service environments. Journal of Retailing, $76(2), 193-218$.

Dar, V. (2020, September 13). From FOMO to JOMO: Embracing the joy of missing out. Financial Express.

Dash, A. (2012, July 19). JOMO! Retrieved from http://anildash.com/2012/07/19/jomo/

Dash, A. (2014, October 8). Mo' JOMO. Retrieved from https://anildash.com/2014/10/08/mo_jomo/

Decembrele, B. (2018, July 11). Your workplace guide to summer vacation. LinkedIn.

Dhaliwal, N. (2020). From FOMO to JOMO: Why I now prefer a life less risky. The Guardian.

Dodgson, L. (2018a, July 26). 'JOMO' is the joy of missing out- here are 3 ways people find happiness in not being involved. Business Insider.

Dodgson, L. (2018b, April 24). Here's what's really going on in your brain when you experience 'FOMO'- The fear of missing out. Business Insider.

Felepchuk, L. (2020). What the heck is the new travel trend "JOMO?" Canada.com. Retrieved June 1, 2020, from https://o.canada.com/travel/what-the-heck-is-the-new-travel-trend-jomo

Fernandez, L., \& Matt, S. (2020, April 7). Instead of FOMO, Covid-19 demands we embrace JOMO- the joy of missing out. The Washington Post. 
Fuller, K. (2018, July 26). JOMO: The joy of missing out: JOMO is the emotionally intelligent antidote to FOMO. Psychology Today.

Gabaji, M. (2020, June 1). You've Heard of FOMO, Now Get Ready for FOGO and JOMO. Lifehacker.

Goldbaum, C. (2020, May 18). Thinking of buying a bike? Get ready for a very long wait. New York Times.

Harder, A. (2020, October 5). In a pandemic winter, dinner comes with a side of propane. Axios.

Herman, D. (2000). Introducing short-term brands: A new branding tool for a new consumer reality. Journal of Brand Management, 7(5), 330-340.

Herman, D. (2011). The Fear of Missing Out. Retrieved May 16, 2020, from http://fomofearofmissingout.com/fomo

Hill, R.P., Martin, K.D., \& Chaplin, L.N. (2012). A tale of two marketplaces: Consumption restriction, social comparison, and life satisfaction. Marketing Letters, 23(3), 731-744.

J. Walter Thompson Intelligence. (2011, May 3). FOMO: Fear of missing out.

Kang, I., Cui, H., \& Son, J. (2019). Conformity consumption behavior and FOMO. Sustainability, 11(17), 4734.

Kary, T. (2020, May 13). Stockpiking Germaphobes Ignite Unlikely Boom: Appliances. Bloomberg.

Lahiri, S. (2020, October). Five Tips on How to Deal with FOMO. The Newscastle Tab.

Lai, C., Altavilla, D., Ronconi, A., \& Aceto, P. (2016). Fear of missing out (FOMO) is associated with activation of the right middle temporal gyrus during inclusion social cue. Computers in Human Behavior, 61, 516-521.

Miller, D. (2018, December 26). CBS Morning Show.

Milyavskaya, M., Saffran, M., Hope, N., \& Koestner, R. (2018). Fear of missing out: Prevalence, dynamics, and consequences of experiencing FOMO. Motivation and Emotion, pp. 1-13.

OnePoll. (2020, July). Quarantine Quality Time. JuicePLUS.

Pandey, E. (2020, April 4). Coronavirus reshapes American families. Axios.

Pearson, B. (2020, October 22). 'Forward Buying' is the next state of anxious spending. Here's what retailers should know. Forbes.

Phelan, H. (2018, July 12). How to make this the summer of missing out. The New York Times.

Przybylski, A.K., Murayama, K., DeHaan, C.R., \& Gladwell, V. (2013). Motivational, emotional, and behavioral correlates of fear of missing out. Computers in Human Behavior, 29(4), 1841-1848.

Rees, M. (2017). FOMO vs. JOMO: How to embrace the joy of missing out. Whole Life Challenge.

Riordan, B.C., Flett, J.A., Hunter, J.A., Scarf, D., \& Conner, T.S. (2015). Fear of missing out (FoMO): The relationship between FoMO, alcohol use, and alcohol-related consequences in college students. Journal of Psychiatry and Brain Functions, 2(1), 9.

Saleh, M.A.H. (2012). An investigation of the relationship between unplanned buying and post-purchase regret. International Journal of Marketing Studies, 4(4), 106.

Sanz, A. (2015, July 29). What's the Psychology Behind the Fear of Missing Out? Slate.

Schreckinger, B. (2014). The home of FOMO. Boston Magazine.

Seong-yoon, K. (2019). Younger. Season 6, Ep 12. New York, NY: TVLand.

Taylor, D.G. (2018). Social media usage, FOMO, and conspicuous consumption: An exploratory study: An abstract. In Academy of Marketing Science World Marketing Congress (pp. 857-858). Springer, Cham.

Wieczner, J. (2020, May 18). The case of the missing toilet paper: How the coronavirus exposed US supply chain flaws. Fortune 500.

Wolniewicz, C.A., Tiamiyu, M.F., Weeks, J.W., \& Elhai, J.D. (2018). Problematic smartphone use and relations with negative affect, fear of missing out, and fear of negative and positive evaluation. Psychiatry Res., 262, 618-623.

Wortham, J. (2012, August 25). Turn off the phone (and the tension). The New York Times.

Yi, S., \& Baumgartner, H. (2008). Motivational compatibility and the role of anticipated feelings in positively valenced persuasive message framing. Psychology \& Marketing, 25(11), 1007- 1026. 